\title{
OFICINA DE CAPACITAÇÃO PARA IMPLANTAÇÃO DE EQUIPES DE SAÚDE DA FAMÍLIA
}

\author{
Janete Elza Felisbino ${ }^{1}$ \\ Ivete Maria Ribeiro ${ }^{2}$
}

\section{SITUAÇÃO QUE GERA A NECESSIDADE DE CAPACITAÇÃO}

O programa de saúde da família como estratégia prioritária de mudança do modelo assitencial e reforço à reorganização do Sistema Único de Saúde, visa promover a qualidade da assistência, aumentar o grau de responsabilidade técnica e gerencial e promover a eqüidade . Entretanto, percebe-se que as equipes de saúde da família são ...que todos os envolvidos no Sistema Local em Saúde participem da capacitação, incluindo o Secretário Municipal de Saúde e outros profissionais que estarão direta ou indiretamente atuando junto à equipe do PSF.

compostas em sua maioria por profissionais cuja

formação não foi dirigida para este perfil, necessitando de capacitação/ informações acerca da utilização adequada da estratégia do PSF, possibilitando a implementação correta do modelo, desde o cadastramento/mapeamento até o planejamento inicial das ações de saúde á comunidade adscrita da área de atuação da equipe.

\section{OBJETIVOS}

Instrumentalizar a equipe para a utilização adequada da estratégia da saúde da família .

Reorganizar o serviço da unidade que presta assistência á saúde da comunidade adscrita da área de atuação da equipe de saúde. saúde.

Promover a participação efetiva da população nas determinação/ planejamento das ações de

Socializar conceitos entre os membros da equipe : enfermeiro, médico, auxiliares de enfermagem, agentes comunitários de saúde, e outros.

Caracterizar a situação do sistema local ( municipal) de saúde, identificando possibilidade de atenção á saúde no sistema de referência e contra referência (interna e externa).

Discutir e internalizar as funções do membros da equipe de saúde da família, promovendo a interdisciplinaridade .

\section{MATERIAIS E MÉTODOS}

Carga Horária : Oficina e aula prática : 68horas/aula

Prática supervisionada: 24horas/aula

1 Doutoranda em Ciências Empresariais, Mestre em Assistência de Enfermagem, Especialista em Planejamento e Gerência de Serviços de Saúde. Coordenadora do Curso de Especialização em Saúde da Família e do Curso de Graduação em Enfermagem da Universidade do Sul de Santa Catarina - UNISUL. Coordenadora do $4^{\circ}$ Núcleo de Estudos e Capacitação em Saúde da Família do Pólo de Formação e Capacitação do Estado de Santa Catarina.

2 Mestre em Assistência de Enfermagem e Especialista em Metodologia da Pesquisa. Professora do Curso de Graduação em Enfermagem da Universidade do Sul de Santa Catarina - UNISUL. Vice Coordenadora do $4^{\circ}$ Núcleo de Estudos e Capacitação em Saúde da Família do Pólo de Formação e Capacitação do Estado de Santa Catarina. 
Recursos didáticos - pedagógicos : Oficina de trabalho coletivo; aula expositiva dialogada; pesquisa de campo; exposição e discussão de vídeos; problematização/construtivista; elaboração de planejamento estratégico participativo a ser executado pela equipe do PSF.

Conteúdo Programático : O conteúdo programático é dividido por momentos e envolve etapas de concentração e dispersão:

\section{Momento ( concentração)}

1. Seminário sobre os aspectos históricos da saúde pública no Brasil. Delineia-se a caminhada histórica da saúde pública que culminou na estratégia da saúde da família .

2. Base conceitual da estratégia da saúde da família - a equipe desenha o cenário que acredita ser a estratégia de saúde da família e seus componentes básicos. Através de um debate interativo discute - se os conceitos chaves .

3. Sistema de Informação Ambulatorial Básica - SIAB - apresenta -se a conceituação básica e faz - se o estudo das fichas de cadastramento e fichas marcadoras. Faz - se também uma discussão sobre mapeamento, com apresentação de vídeo e simulações de como mapear a área .

\section{2ㅇomento ( dispersão)}

A Secretaria Municipal de Saúde junto com a equipe inicia o processo de sensibilização da comunidade para a implantação do PSF, anunciando nos principais meios de comunicação o processo de instalação do novo modelo de assistência á saúde.

A equipe inicia o cadastramento e mapeamento da área adscrita, e o atendimento na unidade de saúde, sempre orientando e informando a população acerca da proposta do PSF.

\section{Momento ( concentração)}

Os instrutores fazem uma supervisão "in loco", para detectar e discutir com a equipe as dificuldades/ facilidades encontradas na execução do mapeamento e cadastramento, e as atividades na unidade de saúde.

\section{4ำ Momento ( dispersão)}

A equipe faz a Caracterização da Situação de Saúde do Município (aspectos demográficos, sócio - econômicos, educação, abrangência rural e urbana, aspectos epidemiológicos, recursos materiais e humanos e financeiros na área da saúde, entre outros).

A equipe faz a Caracterização da Unidade Básica de Saúde (estrutura física, recursos materiais, recursos humanos, normas e rotinas, medicamentos a disposição da população, exames laboratoriais radiológicos e outros, referência e contra - referência, entre outros)

A equipe realiza entrevistas com os Trabalhadores da Unidade de Saúde, os Usuários da Unidade de Saúde e com o Administrador da Unidade de Saúde , conforme roteiro pré estabelecido.

\section{Momento ( concentração)}

Terminado o cadastramento da população adscrita e as entrevistas já citadas, inicia - se o planejamento estratégico em saúde. 
A equipe descreve o que entende por planejamneto, através da confecção de cartazes com recortes e desenhos ou frases e passa - se a discussão através de seminário dos assuntos descritos abaixo :

1. História da introdução do planejamento estratégico na América Latina.

2. Pressupostos teórico - metodológicos e bases fundamentais de algumas correntes teóricas sobre planejamento estratégico em saúde: Carlos Matus; Mario Testa e Escola de Medelin

3. Fases do Planejamento, propostas por Felisbino e Nunes(1996)

\section{6ำ Momento ( concentração)}

Início ás atividades do planejamento :

1. Delimitação dos problemas de saúde / Diagnóstico de saúde

Através de trabalho de grupo, reunindo o resultado das atividades já executadas dá - se início ao levantamento de problemas por micro - área . Instrumentos utilizados : caracterização do município e da unidade de saúde, cadastramento, mapeamento, entrevistas realizadas. A equipe lista todos os problemas, suas possíveis causas e possíveis soluções .

\section{7ำ Momento ( dispersão)}

A equipe realiza reuniões com as comunidades de cada micro - área, para apresentação dos membros da equipe de saúde, proposta do PSF - modelo de atenção á saúde e dos problemas que foram identificados naquela micro - área, para que estes possam opinar acerca das possíveis causas , soluções e dizer como percebem este ou aquele problema. Neste momento a equipe estabelece com a comunidade uma relação de co - responsabilidade e co - participação na busca da melhor alternativa para solucionar os problemas encontrados. Neste dia também são escolhidos os representantes para formar o Conselho Local de Saúde.

\section{Momento ( concentração )}

\section{Determinação/ operacionalização / acompanhamento e avaliação das ações de saúde}

Após a realização das reuniões com a comunidade de todas as micro - áreas da população adscrita , a equipe se reúne para consolidação do plano de ação inicial para solucionar os problemas identificados em cada micro - área, estabelecendo para cada problema identificado, objetivos , ações , estratégias, envolvidos , cronograma , avaliação e orçamento. Colocados em uma planilha que permita o acompanhamento diário da execução. Ao estabelecer o plano a equipe leva em conta as questões abordadas pela comunidade nas reuniões, inclusive em relação ao estabelecimento de prioridades. Neste momento são realizados uma série de ensaios para a aprendizagem da confecção do planejamento e estabelecimento de prioridades.

Estalecimento do cronograma de trabalho da equipe de saúde em todos os dias da semana ( consultas, reunião de equipe, visita domiciliar, reunião de grupos terapêuticos, entre outros).

\section{9ำMomento (dispersão)}

Elaboração do planejamento inicial ( digitação) e entrega ao instrutor . Sugere - se avaliação do planejamento após um ano de atuação . 


\section{RESULTADOS}

. Internalização pela equipe do PSF , da estratégia da saúde da família. -área.

. Cadastramento da população adscrita da área de abrangência da equipe de saúde, por micro

. Elaboração do diagnóstico de saúde inicial e planejamento das ações de saúde .

. Confecção do mapa inteligente da área de atuação da equipe por micro - área .

. Implantação do Sistema de Atenção Básica em Saúde - SIAB.

\section{CONCLUSÕES E RECOMENDAÇÕES}

Diante das experiências de capacitação para implantação da estratégia da saúde da família e os resultados obtidos, faz-se as seguintes conclusões e recomendações :

a) que todos os envolvidos no Sistema Local em Saúde participem da capacitaçãc, incluindo o Secretário Municipal de Saúde e outros profissionais que estarão direta ou indiretamente atuando junto à equipe do PSF;

b) que as capacitações tenham momentos de dispersão e concentração, para oportunizar a aplicação prática dos conhecimentos, ou seja, a discussão da prática e a adequação da teoria à realidade onde a equipe vai atuar;

c) que a equipe de instrutores faça supervisão "in loco", permitindo aos membros da equipe resolver dúvidas ou problemas relacionados á sua prática diária, na implantação do serviço de saúde da família;

d) que as escolas de formação de profissionais na área da saúde,superior e ensino médio, incluam em seus currículos conteúdos que permitam a internalização da atenção primária em saúde e a estratégia de saúde da família; e

e) que as capacitações permitam a construção do modelo que está posto, através da instrumentalização dos profissionais para a mudança do modelo assistencial, que requer uma mudança de mentalidade em relação a assistência á saúde. 